\title{
Reclassification of the Crenarchaeal Orders and Families in Accordance with 16S rRNA Sequence Data
}

\author{
S. BURGGRAF, ${ }^{*}$ H. HUBER, AND K. O. STETTER \\ Lehrstuhl für Mikrobiologie und Archaeenzentrum, Universität Regensburg, 93053 Regensburg, Germany
}

\begin{abstract}
A phylogenetic analysis of all validly published members of the Crenarchaeota, including several new isolates from our laboratory, suggests three orders within this archaeal kingdom. The Thermoproteales consist of both the rod-shaped, hyperthermophilic, neutrophilic representatives of the Thermoproteaceae and the members of the new family Thermofilaceae. The Sulfolobales harbor all thermoacidophilic, coccoid organisms. The neutrophilic, hyperthermophilic cocci are members of a new order tentatively named "Igneococcales." This order comprises two families, the Desulfurococcaceae, characterized by maximal growth temperatures of up to $100^{\circ} \mathrm{C}$, and the new family Pyrodictiaceae, for which optimal growth occurs at temperatures above $100^{\circ} \mathrm{C}$.
\end{abstract}

Phylogenetic analyses based on 16S rRNA sequence comparisons demonstrated that the archaeal domain of life consists of two kingdoms, the Euryarchaeota and the Crenarchaeota (34). All Crenarchaeota are thermophilic or hyperthermophilic organisms, and they have been isolated from continental or submarine hydrothermal systems or from hot anthropogenic biotopes such as smoldering refuse piles $(3,11,13,18,27,30$, 38). Their classification has been mainly based on physiological and biochemical properties, since only a few $16 \mathrm{~S}$ rRNA sequences from these organisms have been available. Two orders within this group have been described, the Sulfolobales (29) and the Thermoproteales (35). The latter comprises two validly published families, the Thermoproteaceae (38) and the Desulfurococcaceae (37). The genera Pyrodictium, "Thermodiscus," and Staphylothermus were tentatively placed in the Thermoproteales (35). A $16 \mathrm{~S}$ ribosomal-DNA (rDNA)-based classification of the order Sulfolobales, including all described thermoacidophilic species, was published recently (12), demonstrating the group to be monophylogenetic. Here we present a complete phylogenetic analysis of all cultivated members of the Crenarchaeota, including several new isolates. Based on our results we reclassify the orders and families within this archaeal kingdom.

\section{MATERIALS AND METHODS}

Strains and culture conditions. Pyrodictium abyssi DSM $6158^{\mathrm{T}}$ (24), Hyperthermus butylicus DSM 5456 ${ }^{\mathrm{T}}$ (36), Staphylothermus marinus DSM $3639^{\mathrm{T}}(11)$, "Thermosphaera aggregans" M11TL (17), "Desulfurococcus saccharovorans" V24K (28), "Thermodiscus maritimus" S2 (28), and "Thermofilum librum" V24N (28) were grown as described previously. Pyrolobus fumarii 1A (4), "Igneococcus islandicus" Kol8 (6), isolate OC11 (15), isolate CB9 (16), and isolate S10TFL (16) are novel, hyperthermophilic isolates characterized in our laboratory.

Isolation of nucleic acids and amplification of the $16 \mathrm{~S}$ rRNA gene. DNAs of all organisms were prepared as described previously $(1,22)$. The nearly complete $16 \mathrm{~S}$ rDNA was amplified by PCR $(25,26)$ in a Perkin-Elmer Gene Amp PCR System 9600 with Perkin-Elmer AmpliTaq DNA polymerase and a standard PCR protocol. The primers used in the amplification corresponded to positions 8 to 23 (7) and either 1390 to 1407 (23) or 1492 to $1511(20)$ in the 16S rRNA sequence of Escherichia coli (5). The amplified PCR products were purified and concentrated in a Microcon 100 column (Amicon).

Sequencing and data analyses. Both strands of the PCR products were sequenced directly by using an AmpliCycle sequencing kit (Perkin-Elmer, developed and manufactured by Roche Molecular Systems, Inc., Branchburg, N.J.) with $\left[{ }^{33} \mathrm{P}\right] \mathrm{dCTP}$ for internal labeling. The following forward and reverse sequencing primers, identical or complementary to conserved sequences in archaeal $16 \mathrm{~S}$ rRNA, were used: 338aR (5' CTGSTGCRCCCCGTAGGGCC $3^{\prime}$ ), 524aR (5' GSNGCYGGTRTTACCGCGGC 3'), 750aR (5' TTCGBCCCTCACCGTCGG

* Corresponding author. Mailing address: Lehrstuhl für Mikrobiologie und Archaeenzentrum, Universität Regensburg, Universitätsstrasse 31, 93053 Regensburg, Germany. $\left.3^{\prime}\right), 890 \mathrm{aR}$ (5' TTTCAGYCTTGCGRCCGTAC 3'), 1044aR (5' GGCCATG CACCWCCTCTC 3'), 1101aR (5' GGYRSGGGTCTCGCTCGTT $3^{\prime}$ ), 1206aR (5' GCCCSGGGGDTTCGGGGC $3^{\prime}$ ), 364aF (5' CGGGGYGCASCAG GCGCGAA $\left.3^{\prime}\right)$, 533F (5' TGBCAGCMGCCGCGGTAA $\left.3^{\prime}\right), 797 \mathrm{aF} \quad\left(5^{\prime}\right.$ GCRAASSGGATTAGATACCC $\left.3^{\prime}\right)$, and 1060aF (5' GAGAGGWGGTG CATGGCC $3^{\prime}$ ). The derived sequences were aligned with a set of representative archaeal sequences (obtained from the Ribosomal Database Project [21]) by using the ARB program from the Department of Microbiology of the Technical University in Munich (31) (kindly provided by W. Ludwig and O. Strunk). For the calculations, only positions present in all analyzed sequences (57 to 1370) and with unambiguous alignments were used, for a total of 1,240 positions. Pairwise evolutionary distances were calculated from percent similarities with a modified Jukes and Cantor correction $(19,32)$. Dendrograms were calculated with the DeSoete program (10) provided by the Ribosomal Database Project and with the neighbor-joining, maximum-parsimony (Phylip package), and maximum-likelihood (fastDNAml) programs included in the ARB package. To check for artificially deep branchings due to a high $\mathrm{G}+\mathrm{C}$ content of the analyzed $16 \mathrm{~S}$ rRNA sequences, all calculations were also performed with only transversions (33).

Nucleotide sequence accession numbers. The sequences of the organisms were deposited in the EMBL Nucleotide Sequence Database with the following accession numbers: Pyrodictium abyssi, X99559; H. butylicus, X99553; S. marinus, X99560; "Thermosphaera aggregans," X99556; "D. saccharovorans," X99558; "Thermodiscus maritimus," X99554; "Thermofilum librum," X99557; Pyrolobus fumarii, X99555; " $I$. islandicus," X99562; strain OC11, X99561; strain CB9 X99563; and strain S10TFL, X99564.

\section{RESULTS AND DISCUSSION}

For a phylogenetic analysis of the Crenarchaeota, we determined nearly complete $16 \mathrm{~S}$ rDNA sequences for the alreadydescribed species S. marinus, $H$. butylicus, and Pyrodictium abyssi. In addition the $16 \mathrm{~S}$ rDNAs from the new organisms Pyrolobus fumarii, "Thermosphaera aggregans," "D. saccharovorans," "Thermodiscus maritimus," "I. islandicus," and "Thermofilum librum" and from the isolates S10TFL, CB9, and OC11 from our laboratory were sequenced.

All of the algorithms utilized to derive the phylogenetic tree (neighbor joining, maximum parsimony, and maximum likelihood) yielded the same tree topology (Fig. 1). Calculations, considering only transversions, to detect artificial clustering due to similarities in the $\mathrm{G}+\mathrm{C}$ contents of the sequences (33) revealed no significant differences in the tree topologies, with the exception of the isolate CB9 (see below). According to the phylogenetic tree, the kingdom Crenarchaeota is composed of three major branches corresponding to three orders, the Thermoproteales, the Sulfolobales, and a new order tentatively named "Igneococcales."

The rod-shaped organisms of the order Thermoproteales form a distinct cluster within the Crenarchaeota. Two branches are evident within the Thermoproteales, one which can be assigned to the family Thermoproteaceae and one which can be assigned to the new family Thermofilaceae. This separation is in 


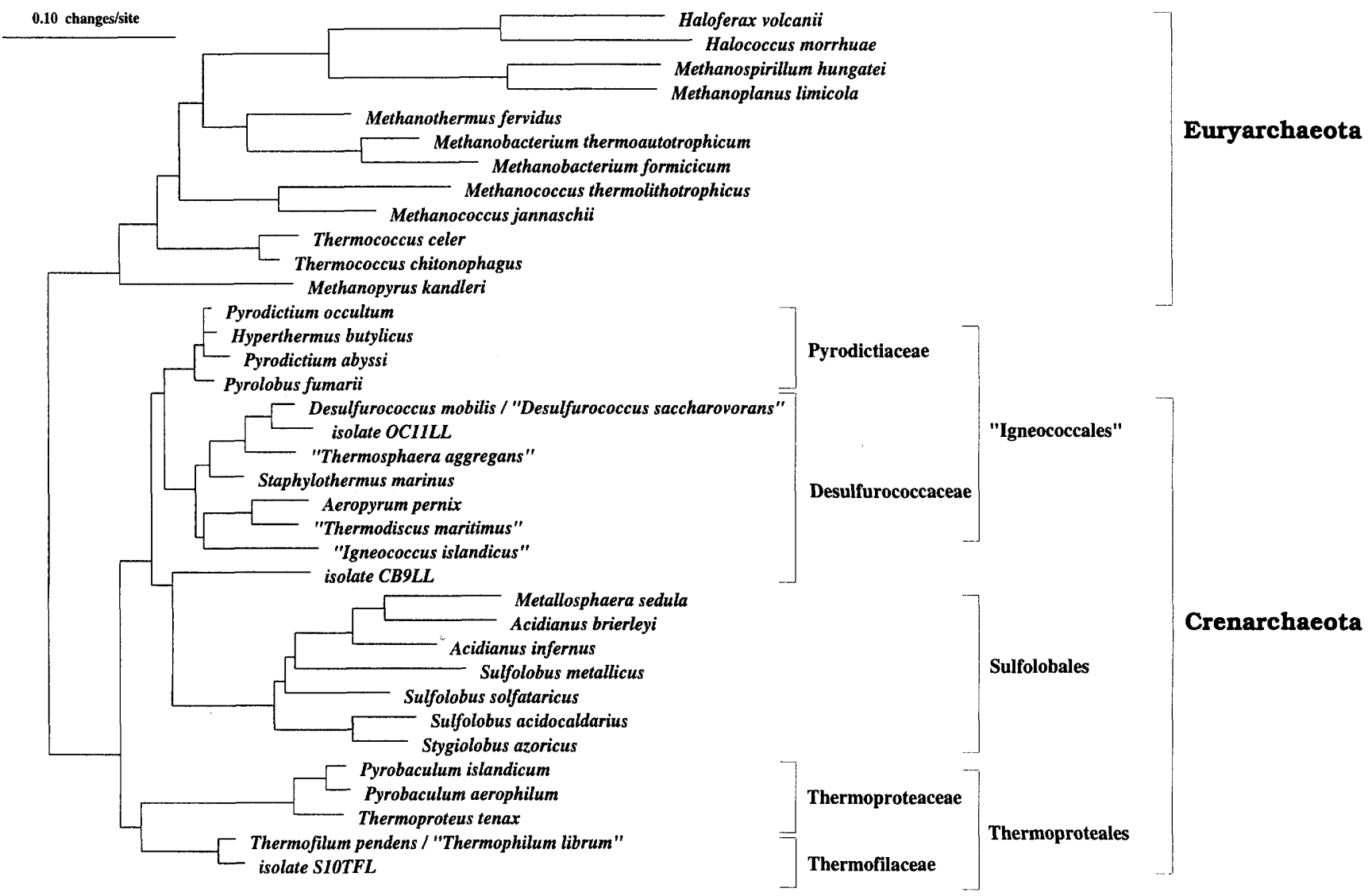

FIG. 1. Phylogenetic tree derived from 16S rDNA sequence data for the members of the Crenarchaeota and for some representatives from the major euryarchaeal groups. The tree was derived with the maximum-parsimony program. The scale bar indicates 10 estimated changes per 100 nucleotides.

agreement with morphological characteristics. The cell diameters of members of the Thermoproteaceae are at least $0.4 \mu \mathrm{m}$, while the filamentous cells of members of the Thermofilaceae exhibit cell diameters of less than $0.35 \mu \mathrm{m}$. Despite the large phylogenetic distance between these families of more than 10 estimated changes per 100 nucleotides (data not shown), most treeing programs show a common root. Only the calculation with the DeSoete program results in a separate branching point for the two lineages. While Thermofilum pendens and "Thermofilum librum" have identical $16 \mathrm{~S}$ rDNA sequences, the new isolate S10TFL, which has been isolated from Obsidian Pool, a hot spring at Yellowstone National Park, exhibits a phylogenetic distance from these organisms of $2.2 \%$. More interestingly, its $16 \mathrm{~S}$ rDNA sequence is identical to the sequence of clone pJP6 obtained by phylogenetic analysis of DNA directly extracted from sample material of this hot spring (1).

A detailed analysis of the members of the second branch, the order Sulfolobales, has been described recently (12) and is in full agreement with our results. All members of this order are regularly or irregularly coccus-shaped thermoacidophiles. However, the present taxonomy of the Sulfolobales does not always coincide with the results of the $16 \mathrm{~S}$ rDNA-based phylogenetic investigations. The phylogeny, especially of members of the genus Sulfolobus, would justify splitting this group into three different genera or even families (Fig. 1). However, due to the lack of physiological or biochemical characteristics significant for defining these taxa, it has been suggested that the genus not be reclassified at present (12).
All representatives of the third cluster (order) are coccoid or disc-shaped anaerobic (with the exception of Aeropyrum pernix) hyperthermophiles that grow at neutral pHs. Therefore, we propose the name "Igneococcales" for the new order. Two families, the Pyrodictiaceae and the Desulfurococcaceae, are evident. The family Pyrodictiaceae, a phylogenetic group of organisms characterized by optimal growth temperatures above $100^{\circ} \mathrm{C}$, consists of the genera Pyrodictium and Hyperthermus and the new genus Pyrolobus (4). The maximum phylogenetic distance between these genera of only 1.5 estimated changes per 100 nucleotides demonstrates their close relationship (data not shown). However, they exhibit significant differences in morphology and metabolism. The two Pyrodictium species are coccoid cells connected by a network of hollow fibers. This network is missing in Hyperthermus and Pyrolobus. Pyrodictium and Hyperthermus grow strictly anaerobically by chemolithoautotrophic or heterotrophic reduction of elemental sulfur. Pyrolobus gains energy by $\mathrm{H}_{2}$ oxidation with nitrate, $\mathrm{S}_{2} \mathrm{O}_{3}{ }^{2-}$, or a low concentration of $\mathrm{O}_{2}$ as the electron acceptor.

The family Desulfurococcaceae is phylogenetically clearly separate from the Pyrodictiaceae (Fig. 1). The coccoid or discshaped organisms of the Desulfurococcaceae are hyperthermophiles with an optimal growth temperature above $85^{\circ} \mathrm{C}$ and, in contrast to the Pyrodictiaceae, a maximum growth temperature not higher than $100^{\circ} \mathrm{C}$. The organisms grow chemolithoautotrophically by sulfur reduction to $\mathrm{H}_{2} \mathrm{~S}$ with $\mathrm{CO}_{2}$ as the sole carbon source or heterotrophically by sulfur respiration of various organic substrates or by fermentation or aerobic respiration. One branch of this family harbors $S$. marinus, 
"Thermosphaera aggregans," the isolate OC11, and the sequence-identical species Desulfurococcus mobilis and "D. saccharovorans." "I. islandicus" (6), "Thermodiscus maritimus" (28), and the only obligate aerobic member of the Desulfurococcaceae, $A$. pernix (27), represent a separate branch. Only one tree calculation, based on the least-squares distance method of DeSoete (10), showed an affiliation of these organisms to the Pyrodictiaceae, and therefore the tree topology shown in Fig. 1 is more likely.

The phylogenetic affiliation of the novel organism CB9, a coccoid, hyperthermophilic, anaerobic, neutrophilic heterotroph isolated from Lake Tanganyika (Africa) (16), is still somewhat unclear. While analyses constrained by only transversions and the normal DeSoete analysis show an affiliation of this organism with the "Igneococcales," all other calculations show isolate CB9 as the deepest branch of the Sulfolobales (Fig. 1). Therefore, the exact determination of the phylogenetic position of this isolate has to await detailed physiological and biochemical characterizations and/or the isolation of closely related strains.

Due to the different rates of evolution in various branches within the phylogenetic tree, it is very difficult to define specific phylogenetic distances separating classes of taxa. rRNAs from hyperthermophiles have a high $\mathrm{G}+\mathrm{C}$ content, which stabilizes the secondary structure at high temperatures. This results in a lower rate of sequence change than that observed for mesophilic organisms. Therefore it is impossible to use the phylogenetic distances which, e.g., separate the orders of the methanogens as criteria for separation of hyperthermophilic, crenarchaeal taxa. Although there is a much smaller phylogenetic distance between the "Igneococcales" and the Thermoproteales than there is between, e.g., the Methanococcales and the Methanobacteriales, they form distinct phylogenetic clusters and are also well separated by different morphological, biochemical, and physiological properties.

For a long time the Crenarchaeota were regarded as a branch of the sulfur-metabolizing hyperthermophiles. Now, the isolation of several new members of this kingdom demonstrates a great variety of physiologically diverse organisms. Even organisms which are inhibited by sulfur, like Pyrobaculum aerophilum or Pyrolobus fumarii, are included in this kingdom. Recently an in situ analysis of a hot spring in Yellowstone National Park revealed a very rich diversity of crenarchaeal small-subunit rRNA sequences $(1,2)$. By the same method, sequences from mesophilic Crenarchaeota, which might represent a major fraction of the picoplankton in the oceans (9), were detected $(8,14)$. This indicates that there are many, as-yet-uncultivated, Crenarchaeota that may lead to the identification of further families or orders within this archaeal kingdom.

Emendation of the order Thermoproteales Zillig et al. 1981. Cells are rods from about 0.1 to $0.5 \mu \mathrm{m}$ in diameter and from 1 to almost $100 \mu \mathrm{m}$ in length. Septa have not been encountered. Gram negative. Anaerobic to facultatively anaerobic. Hyperthermophilic (optimal growth temperature above $80^{\circ} \mathrm{C}$ ). Chemolithoautotrophic growth by reduction of elemental sulfur according to the reaction $\mathrm{H}_{2}+\mathrm{S}^{0} \rightarrow \mathrm{H}_{2} \mathrm{~S}$ with $\mathrm{CO}_{2}$ as the sole carbon source or by sulfur respiration of various organic substrates yielding $\mathrm{CO}_{2}$ and $\mathrm{H}_{2} \mathrm{~S}$. Some genera are able to produce energy by respiration with $\mathrm{O}_{2}$ or nitrate as the electron acceptor. S-layer of the cell envelope composed of protein or glycoprotein subunits in hexagonal dense packing, devoid of muramic acid. Lipids contain glycerol ethers of polyisoprenoid $\mathrm{C}_{40}$ and, in lesser amounts, $\mathrm{C}_{20}$ alcohols. Transcription is resistant to rifampin and streptolydigin. RNA polymerase exhibits a complex BAC-component pattern. $\mathrm{G}+\mathrm{C}$ content of genomic DNA, 46 to $57 \%$. Widely distributed in solfataric hot springs and submarine hydrothermal systems. The order so far comprises two families, the Thermoproteaceae and the Thermofilaceae fam. nov.

Emendation of the family Thermoproteaceae Zillig et al. 1981. Rigid rods, with lengths between 1.5 and $8 \mu \mathrm{m}$ and diameters of 0.4 to $0.5 \mu \mathrm{m}$. Energy produced chemolithoautotrophically by reduction of elemental sulfur with $\mathrm{H}_{2}$ by using $\mathrm{CO}_{2}$ as the sole carbon source, by sulfur respiration utilizing various organic substrates, or by respiration with $\mathrm{O}_{2}$ or nitrate as the electron acceptor. So far the family harbors two genera, Thermoproteus and Pyrobaculum.

Description of the family Thermofilaceae fam. nov. Thermofilaceae (Ther.mo.fi.la'ce.ae. M.L. neut. n. Thermofilum type genus of the family; -aceae to denote a family; M.L. fem. pl. $\mathrm{n}$. Thermofilaceae the Thermofilum family). Thin rods 0.15 to $0.35 \mu \mathrm{m}$ in diameter and 1 to $>100 \mu \mathrm{m}$ in length. The family comprises the single genus Thermofilum.

Emendation of the family Desulfurococcaceae Zillig et al. 1982. Coccoid to disc-shaped cells. Hyperthermophilic; optimal growth temperature above $85^{\circ} \mathrm{C}$, maximum growth temperature up to $100^{\circ} \mathrm{C}$. Anaerobic or aerobic. Chemolithoautotrophic growth by sulfur reduction to $\mathrm{H}_{2} \mathrm{~S}$ with $\mathrm{CO}_{2}$ as the sole carbon source. Strictly heterotrophic growth by sulfur respiration of various organic substrates, aerobic respiration, or fermentation. Six genera are known so far: Desulfurococcus, Staphylothermus, Aeropyrum, "Thermosphaera," "Thermodiscus," and "Igneococcus."

Description of the family Pyrodictiaceae fam. nov. Pyrodictiaceae (Pyr.o.dic'ti.a.ce.ae. M.L. neut. n. Pyrodictium type genus of the family; -aceae to denote a family; M.L. fem. pl. n. Pyrodictiaceae the Pyrodictium family). Coccoid to disc-shaped cells. Hyperthermophilic; maximum growth temperature above $100^{\circ} \mathrm{C}$. Either chemolithoautotrophic growth with $\mathrm{H}_{2}$ by reduction of elemental sulfur or thiosulfate to $\mathrm{H}_{2} \mathrm{~S}$ with $\mathrm{CO}_{2}$ as the sole carbon source or growth by fermentation. Some genera gain energy by respiration with $\mathrm{O}_{2}$ or nitrate as the electron acceptor.

\section{ACKNOWLEDGMENTS}

We gratefully acknowledge W. Ludwig and O. Strunk for providing the ARB program and for instruction on its usage. Furthermore, we are indebted to Clifford Brunk for critically reading the manuscript and Nicole Eis for helpful discussions.

This work was supported by the Deutsche Forschungsgemeinschaft (STE 297/10-2)

\section{REFERENCES}

1. Barns, S. M., R. E. Fundyga, M. W. Jeffries, and N. R. Pace. 1994. Remarkable archaeal diversity detected in a Yellowstone National Park hot spring environment. Proc. Natl. Acad. Sci. USA 91:1609-1613.

2. Barns, S. M., R. E. Fundyga, M. W. Jeffries, and N. R. Pace. 1994. Remarkable archaeal diversity in a Yellowstone National Park hot spring, p. 253. In Abstracts of the 94th General Meeting of the American Society for Microbiology 1994.

3. Blöchl, E., S. Burggraf, G. Fiala, G. Lauerer, G. Huber, R. Huber, R. Rachel, A. Segerer, K. O. Stetter, and P. Völkl. 1995. Isolation, taxonomy and phylogeny of hyperthermophilic microorganisms. World J. Microbiol. Biotechnol. 11:9-16.

4. Blöchl, E., R. Rachel, S. Burggraf, D. Hafenbradl, H. W. Jannasch, and K. O. Stetter. 1997. Pyrolobus fumarii, gen. and sp. nov. represents a novel group of archaea, extending the upper temperature limit for life to $113^{\circ} \mathrm{C}$. Extremophiles 1:14-21.

5. Brosius, J., T. J. Dull, D. D. Sleeter, and H. F. Noller. 1981. Gene organization and primary structure of a ribosomal RNA operon from Escherichia coli. J. Mol. Biol. 148:107-127.

6. Burggraf, S. Unpublished data.

7. Burggraf, S., K. O. Stetter, P. Rouviere, and C. R. Woese. 1991. Methanopyrus kandleri: an archaeal methanogen unrelated to all other known methanogens. Syst. Appl. Microbiol. 14:346-351. 
8. DeLong, E. F. 1992. Novel archaea in coastal marine environments. Proc. Natl. Acad. Sci. USA 89:5685-5689.

9. DeLong, E. F., K. Y. Wu, B. B. Prezelin, and V. M. Jovine. 1994. High abundance of Archaea in antarctic marine picoplankton. Nature 371:695697.

10. DeSoete, G. 1983. A least squares algorithm for fitting additive trees to proximity data. Psychometrika 48:621-626.

11. Fiala, G., K. O. Stetter, H. W. Jannasch, T. A. Langworthy, and J. Madon. 1986. Staphylothermus marinus sp. nov. represents a novel genus of extremely thermophilic submarine heterotrophic archaebacteria growing up to $98^{\circ} \mathrm{C}$. Syst. Appl. Microbiol. 8:106-113.

12. Fuchs, T., H. Huber, S. Burggraf, and K. O. Stetter. 1996. 16S rDNA-based phylogeny of the archaeal order Sulfolobales and reclassification of Desulfurolobus ambivalens as Acidianus ambivalens comb. nov. Syst. Appl. Microbiol. 19:56-60.

13. Fuchs, T., H. Huber, K. Teiner, S. Burggraf, and K. O. Stetter. 1995. Metallosphaera prunae, sp. nov., a novel metal-mobilizing, thermoacidophilic archaeum, isolated from a uranium mine in Germany. Syst. Appl. Microbiol. 18:560-566.

14. Fuhrman, J. A., K. McCallum, and A. A. Davis. 1992. Novel major archaebacterial group from marine plankton. Nature 356:148-149.

15. Hafenbradl, D. Unpublished data.

16. Huber, R. Unpublished data.

17. Huber, R., S. Burggraf, T. Mayer, S. M. Barns, P. Rossnagel, and K. O. Stetter. 1995. Isolation of a hyperthermophilic archaeum predicted by in situ RNA analysis. Nature 376:57-58.

18. Huber, R., and K. O. Stetter. 1992. The order Thermoproteales, p. 677-683. In A. Balows et al. (ed.), The prokaryotes, 2nd ed. Springer-Verlag, New York, N.Y.

19. Jukes, T. H., and C. R. Cantor. 1969. Evolution of protein molecules, p. 21-132. In H. N. Munro (ed.), Mammalian protein metabolism. Academic Press, New York, N.Y.

20. Lane, D. J. 1991. 16S/23S rRNA sequencing, p. 115-175. In E. Stackebrand and M. Goodfellow (ed.), Nucleic acid techniques in bacterial systematics. J. Wiley \& Sons, Chichester, U.K.

21. Maidak, B. L., G. J. Olsen, N. Larsen, R. Overbeek, M. J. McCaughey, and C. R. Woese. 1996. The Ribosomal Database Project (RDP). Nucleic Acids Res. 24:82-85.

22. Marmur, J. 1961. A procedure for the isolation of deoxyribonucleic acid from microorganisms. J. Mol. Biol. 3:208-218.

23. Olsen, G. J., D. J. Lane, S. J. Giovannoni, N. R. Pace, and D. A. Stahl. 1986. Microbial ecology and evolution: a ribosomal RNA approach. Annu. Rev. Microbiol. 40:337-365.

24. Pley, U., J. Schipka, A. Gambacorta, H. W. Jannasch, H. Fricke, R. Rachel, and K. O. Stetter. 1991. Pyrodictium abyssi sp. nov. represents a novel heterotrophic marine archaeal hyperthermophile growing at $110^{\circ} \mathrm{C}$. Syst. Appl. Microbiol. 14:245-253.

25. Saiki, R. K., D. H. Gelfand, S. Stoffel, S. J. Scharf, R. Higuchi, G. T. Horn, K. B. Mullis, and H. A. Erlich. 1988. Primer-directed enzymatic amplifica- tion of DNA with a thermostable DNA polymerase. Science 239:487-491.

26. Saiki, R. K., S. J. Scharf, F. Faloona, K. B. Mullis, G. T. Horn, H. A. Erlich, and $\mathbf{N}$. Arnheim. 1985. Enzymatic amplification of $\beta$-globin genomic sequences and restriction site analysis for diagnosis of sickle cell anemia. Science 230:1350-1354

27. Sako, Y., N. Nomura, A. Uchida, Y. Ishida, H. Morii, Y. Koga, T. Hoaki, and T. Maruyama. 1996. Aeropynum pernix gen. nov., sp. nov., a novel aerobic hyperthermophilic archaeon growing at temperatures up to $100^{\circ} \mathrm{C}$. Int. J. Syst. Bacteriol. 46:1070-1077.

28. Stetter, K. O. 1986. Diversity of extremely thermophilic archaebacteria, p 40-74. In T. D. Brock (ed.), Thermophiles: general, molecular and applied microbiology. John Wiley \& Sons, New York, N.Y.

29. Stetter, K. O. 1989. Order III. Sulfolobales ord. nov., p. 2250-2253. In J. T. Staley, M. P. Bryant, N. Pfennig, and J. G. Holt (ed.), Bergey's manual of systematic bacteriology, vol. 3. Williams \& Wilkins, Baltimore, Md.

30. Stetter, K. O., H. König, and E. Stackebrandt. 1983. Pyrodictium gen. nov, a new genus of submarine disc-shaped sulphur reducing archaebacteria growing optimally at $105^{\circ} \mathrm{C}$. Syst. Appl. Microbiol. 4:535-551.

31. Strunk, O., O. Gross, B. Reichel, M. May, S. Herrmann, N. Stuckmann, B. Nonhoff, M. Lenke, A. Ginhart, A. Vilbig, R. Wesytram, T. Ludwig, A. Bode, K. H. Schleifer, and W. Ludwig. ARB: a software environment for sequence data. Nucleic Acids Res., in press.

32. Weisburg, W. G., J. G. Tully, D. L. Rose, J. P. Petzel, H. Oyaizu, D. Yang, L. Mandelco, J. Sechrest, T. G. Lawrence, J. Van Etten, J. Maniloff, and C. R. Woese. 1989. A phylogenetic analysis of the mycoplasmas: basis for their classification. J. Bacteriol. 171:6455-6467.

33. Woese, C. R., L. Achenbach, P. Rouviere, and L. Mandelco. 1991. Archaeal phylogeny: reexamination of the phylogenetic position of Archaeoglobus fulgidus in light of certain composition-induced artefacts. Syst. Appl. Microbiol. 14:364-371.

34. Woese, C. R., O. Kandler, and M. L. Wheelis. 1990 . Towards a natural system of organisms: proposal for the domains Archaea, Bacteria and Eucarya. Proc. Natl. Acad. Sci. USA 87:4576-4579.

35. Zillig, W. 1989. Order II. Thermoproteales, p. 2240-2246. In J. T. Staley, M. P. Bryant, N. Pfennig, and J. G. Holt (ed.), Bergey's manual of systematic bacteriology, vol. 3. Williams \& Wilkins, Baltimore, Md.

36. Zillig, W., I. Holz, D. Janekovic, H.-P. Klenk, E. Imsel, J. Trent, S. Wunderl, V. H. Forjaz, R. Coutinho, and T. Ferreira. 1990. Hyperthermus butylicus, a hyperthermophilic sulfur-reducing archaebacterium that ferments peptides J. Bacteriol, 172:3959-3965.

37. Zillig, W., K. O. Stetter, D. Prangishvilli, W. Schäfer, S. Wunderl, D. Janekovic, I. Holz, and P. Palm. 1982. Desulfurococcaceae, the second family of the extremely thermophilic, anaerobic, sulfur-respiring Thermoproteales. Zentralbl. Bakteriol. Mikrobiol. Hyg. 1. Abt. Orig. C 3:304-317.

38. Zillig, W., K. O. Stetter, W. Schäfer, D. Janekovic, S. Wunderl, I. Holz, and P. Palm. 1981. Thermoproteales: a novel type of extremely thermoacidophilic anaerobic archaebacteria isolated from Icelandic solfataras. Zentralbl. Bakteriol. Mikrobiol. Hyg. 1. Abt. Orig. C 2:205-227. 